\title{
A protocol for the reduction of applied torque on parent vessel during elastase-induced aneurysm formation using rabbit animal models
}

\author{
Sergio A. Pineda-Castillo ${ }^{\mathrm{a}, \mathrm{b}}$, Keely A. Laurence ${ }^{\mathrm{a}}$, Hannah Homburg ${ }^{\mathrm{c}}$, Kar-Ming Fung ${ }^{\mathrm{d}}$, \\ Bradley N. Bohnstedt ${ }^{\mathrm{e}}$, Chung-Hao Lee $\mathrm{a}^{\mathrm{a}, \mathrm{b}, *}$ \\ ${ }^{a}$ Biomechanics and Biomaterials Design Laboratory, The University of Oklahoma, Norman, OK 73019, USA \\ ${ }^{b}$ Institute for Biomedical Engineering, Science and Technology, The University of Oklahoma, Norman, OK 73019, USA \\ ${ }^{c}$ Department of Pathology, The University of Oklahoma Health Sciences Center, Oklahoma City, OK 73104, USA \\ ${ }^{d}$ Department of Neuropathology, The University of Oklahoma Health Sciences Center, Oklahoma City, OK 73104, USA \\ ${ }^{e}$ Department of Neurological Surgery, Indiana University School of Medicine, Indianapolis, IN 46202, USA
}

\begin{abstract}
Endovascular therapies for intracranial aneurysms requires animal models for testing the safety and effectiveness prior to translation to the clinic. Rabbits combined with the elastase and right common carotid artery (RCCA) ligation methods is currently a widely used animal model for endovascular device testing. However, the injection of elastase utilizing angiocatheters may potentially exerts adverse torque to the parent vessel and the optimal aneurysm creation period has not been well investigated. In this study, we present a modification to the elastase/RCCA-ligation method by replacing the angiocatheter with a butterfly catheter. Formation of saccular aneurysms was introduced in New Zealand white rabbits $(n=6)$, and were maintained for 2, 4 and 6 weeks. The formed aneurysms exhibited an elongated geometry and were stable during the study period. We found that the modification in the animal surgery procedure provides improved manipulation of the surgical area, prolonged injection of elastase, and effective degradation of the vascular elastic lamina. Compared to the traditional elastase/RCCA-ligation method, the present technique can more effectively reduce unwanted injury to the parent vessel and, therefore, improved stability of the vasculature for testing the efficacy of newly developed endovascular embolization devices.
\end{abstract}

Keywords: intracranial aneurysm, animal model, endovascular devices, carotid ligation, elastase

\section{Introduction}

Subarachnoid hemorrhage ( $\mathrm{SAH})$ is a type of stroke that is caused by the rupture of an intracranial aneurysm (ICA), and can lead to death or long-term disability. Currently, the average incidence

${ }^{*}$ Corresponding author. 865 Asp Ave., Felgar Hall 219C, Norman, OK 73019, USA.

Email address: ch. lee@ou. edu (Chung-Hao Lee) 
of aneurysm-provoked SAH is still at 6.1 (95\% CI, 4.9-7.5) per 100,000 person-years, in spite of the decreased worldwide prevalence of smoking and high-blood pressure, ${ }^{[1]}$ and the relatively low risk of ICA rupture (0.54 - $1.3 \%$ annually). ${ }^{[2,3]}$ However, ICA rupture risk can increase with multiple cofactors, including sex (females being at higher risk than males), Japanese or Finish descent, aneurysm morphological characteristics and location, among others. ${ }^{[4,5]}$ Specifically, geometrical and location factors lead to a wide variety of aneurysm types, which will determine the treatment of choice.

Current ICA treatment methods include microsurgical clipping and endovascular therapies. Microsurgical clipping utilizes a platinum clip to block blood flow into the ICA, which is highly invasive due to the need of craniotomy. On the other hand, endovascular devices transport occlusive materials into the aneurysm using catheters, which results in reduced in-hospital fatalities, disability and rebleeding, when compared to microsurgical clipping. ${ }^{[6]}$ Therefore, endovascular devices are the preferred method by physicians for aneurysm therapeutics, especially for the elderly and/or patients with aneurysms on the non-middle cerebral artery. ${ }^{[7]}$

Endovascular aneurysm therapy was first introduced with the development of Gugliemi's detachable coils (GDCs), ${ }^{[8,9]}$ a system that utilizes platinum coils to occlude the aneurysm space and prevent intra-aneruysmal flow. Ever since GDCs introduction, several assisting devices, such as balloons and stents, have been developed, further extending the applicability of the system. ${ }^{[10]}$ However, GDCs face limitations such as mass effects, ${ }^{[11]}$ rebleeding, ${ }^{[12]}$ incomplete occlusion and aneurysm recurrence. ${ }^{[13]}$ This has led to the need for the development of endovascular devices that can overcome the limitations and suboptiomal outcomes of GDCs (e.g., coils with dynamic stiffness, ${ }^{[14]}$ hydrogel-coated coils, ${ }^{[15,16]}$ flow diverters, ${ }^{[17]}$ self-expanding nitinol meshes $\left.{ }^{[18,19]}\right)$.

Despite the wide variety of currently available endovascular devices, aneurysm recurrence is still an emerging challenge for the field of endovascular treatment for ICAs. Therefore, different tools have emerged to assess the degree of occlusion provided by endovascular embolization procedures, such as the Raymond-Roy occlusion classification (RROC). The RROC is a clinical standard for angiographic assessment of the degree of occlusion of an aneurysm: RROC-I represents a completely occluded aneurysm; RROC-II represents a lack of occlusion at the neck of the aneurysm (i.e., neck remnant); and RROC-III represents flow of angiographic dye into the aneurysm dome (Fig. 1). Table 1 lists RROC rates achieved after treatment with different marketable endovascular devices, showing that a maximum of $54.4 \%$ patients treated with endovascular methods will have complete occlusion and that the rates of neck and aneurysm remnant are still limited. Specifically, considering that an RROC-III has been demonstrated to pose a substantial risk for aneurysm recurrence and retreatment, ${ }^{[20]}$, it can 
be inferred that the state-of-the-art devices for endovascular embolization cannot prevent aneurysm recurrence. Hence, it is of paramount importance that the newly developed endovascular devices aim to achieve complete and sustained occlusion of ICAs (represented by RROC-I), as much as possible.

With this in mind, the development of biomedical devices requires careful and thorough testing before its translation to the clinic. Specifically, biomedical technology requires the use of animal models that serve as platforms to test the in vivo safety and efficacy of the device. Thus, modeling of ICAs in animals is of fundamental importance for the development of endovascular devices. Animal models for ICA research have been developed for pathological and biological studies, ${ }^{[21]}$ drug testing ${ }^{[22]}$ and device translation. ${ }^{[23]}$ These include mice, rat, rabbit, dog and pig models, where rabbit and rat carotid artery models are the most frequently used.

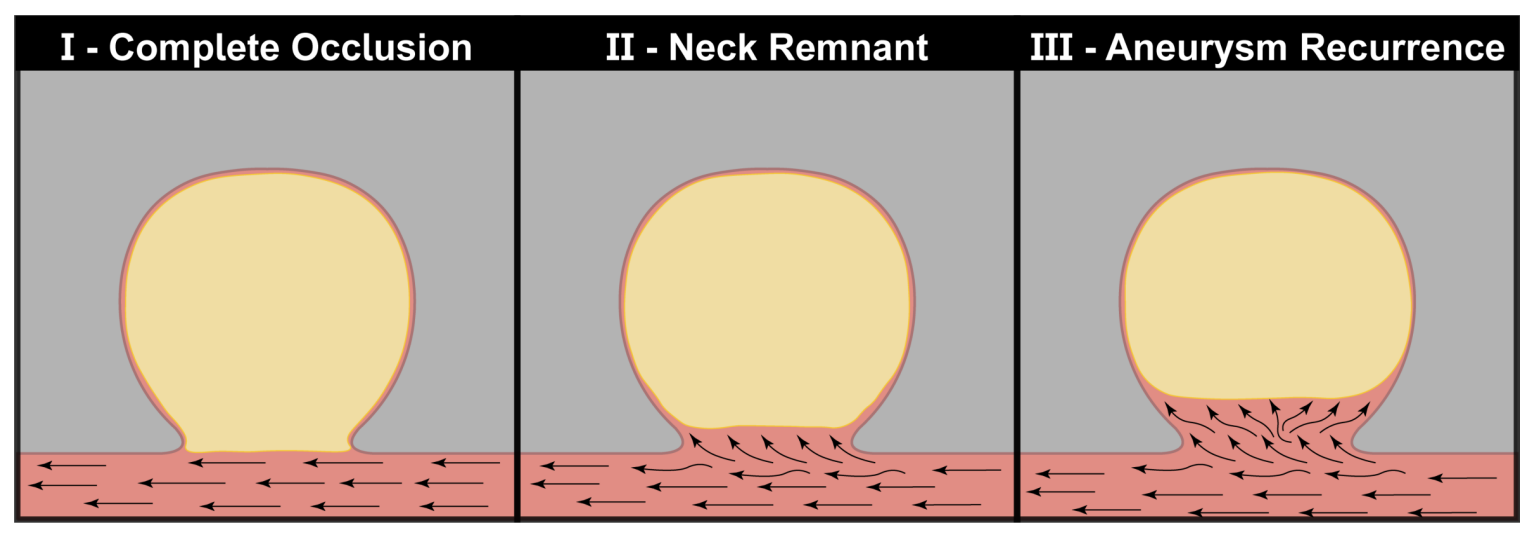

Figure 1: Representation of RROC scale for the assessment of the degree of occlusion of saccular aneurysms.

Table 1: Raymond-Roy Occlusion Classification rates after treatment with current marketable endovascular devices.

\begin{tabular}{|c|c|c|c|}
\hline \multirow{2}{*}{ Device } & \multicolumn{3}{|c|}{ RROC Scale } \\
\cline { 2 - 4 } & I & II & III \\
\hline GDCs $^{[13]}$ & $25.7 \%$ & $32.3 \%$ & $42 \%$ \\
\hline Hydrogel Coils $^{[15]}$ & $54.4 \%$ & $19.7 \%$ & $25.9 \%$ \\
\hline Woven EndoBridge $^{[18]}$ & $53.8 \%$ & $30.8 \%$ & $15.4 \%$ \\
\hline Flow Diverters $^{[24]}$ & $53.8 \%$ & $3.8 \%$ & $11.5 \%$ \\
\hline
\end{tabular}

ICA formation in these animal models can be performed via different methods, including parent artery ligation, elastase injection, among others. (For a review in ICA animal models, see Strange $e t$ $a l .{ }^{[25]}$ ) These methods and their combinations are widely accepted for in vivo testing of endovascular devices. For example, Killer et al.. (2010) used a combination of right common carotid artery ligation (RCCA) and elastase injection to create aneurysms in rabbits for the testing of a hydrogel-coated coil. Also, Herting et al. (2020) and Ding et al. (2016) used similar methods to test a polymer-coated coil and a self-expanding double-layer nitinol mesh for endovascular embolization, respectively. ${ }^{\text {[26,27] }}$ 
In this study, we aimed at improving the execution of the elastase/RCCA-ligation method for the rabbit aneurysm model. Our findings suggest that this modification will improve the surgical procedure for the formation aneurysms and, ultimately, facilitate a more streamlined procedure for testing ICA embolic devices.

\section{Methods}

\subsection{Aneurysm Formation}

Experimental elastase aneurysms were formed in male New Zealand white rabbits (Charles River Laboratories , NY, USA) (weight: $3.0-4.0 \mathrm{~kg}$ ). Rabbits were sedated with an intramuscular injection of Ketamine $(50 \mathrm{mg} / \mathrm{kg})$ and Xylazine $(5 \mathrm{mg} / \mathrm{kg})$. Sedation was maintained using $1-4 \%$ isofluorane inhalation. The RCCA was exposed by placing the anesthesized rabbit in supine position and making an incision between the medial edge of the sternocleidomastoid and the trachea. A clip was tightly secured around the RCCA, close to the brachiocephalic trunk. A silk tie was placed around the artery and tied securely at $1.5 \mathrm{~cm}$ above the aneurysm clip. A $1: 2$ mixture of elastase (BD Millipore) and saline was injected into the RCCA while maintaining the aneurys clip secured. After 20 minutes the aneurysm clip was removed to restore flow. (Fig. 2a). Elastase solution enzymatically degraded the healthy elastic lamina (Fig. 2b.1-2), which debilitated the wall and induced ballooning of the arterial wall (Fig. 2b.3). The incision was closed and covered with triple antibiotic ointment. The rabbit was then moved to a recovery chamber for recover, and monitored daily for 7 days post-surgery.

\subsection{Assessment of Aneurysm Formation}

Rabbits were prepared for angiography at the end of 2, 4, and 6 weeks ( $n=4$, per group) periods using the same anesthetic procedures described previously. The left femoral artery was exposed and an aneurysm clip was placed proximally and the artery was tied about $2 \mathrm{~cm}$ distal to the clip. A small cut was performed and the catheter and the guide wire were inserted. A C-arm angiography device (GE 9800 Omnipaque contrast) was used to confirm that the catheter reached the ascending aorta. Digitally subtracted angiography was then performed to demonstrate the aneurysm. Imaging was performed to assess aneurysm growth and maintenance. After aneurysm visualization, the catheter was positioned in the left ventricle and Euthasol $(1 \mathrm{~mL} / 4.5 \mathrm{~kg})$ were injected. After confirmation of death, the original incision was re-opened to expose the RCCA and resect the aneurysm. The left common carotid artery was also resected as control. Tissues were stored in saline prior to further processing. 
bioRxiv preprint doi: https://doi org/10.1101/2021.10 08.463749; this version posted October 9, 2021. The copyright holder for this preprint (which was not certified by peer review) is the author/funder, who has granted bioRxiv a license to display the preprint in perpetuity. It is made available under aCC-BY-NC 4.0 International license.

Angiographic images were processed to measure aneurysm length $(A L)$ and aneurysm width $(A W)$, using open-source software ImageJ. ${ }^{[28]}$ Measurments were compared at the three imaging timepoints using a one-way ANOVA test. Differences were deemed significant if $p<0.05$.

(a)

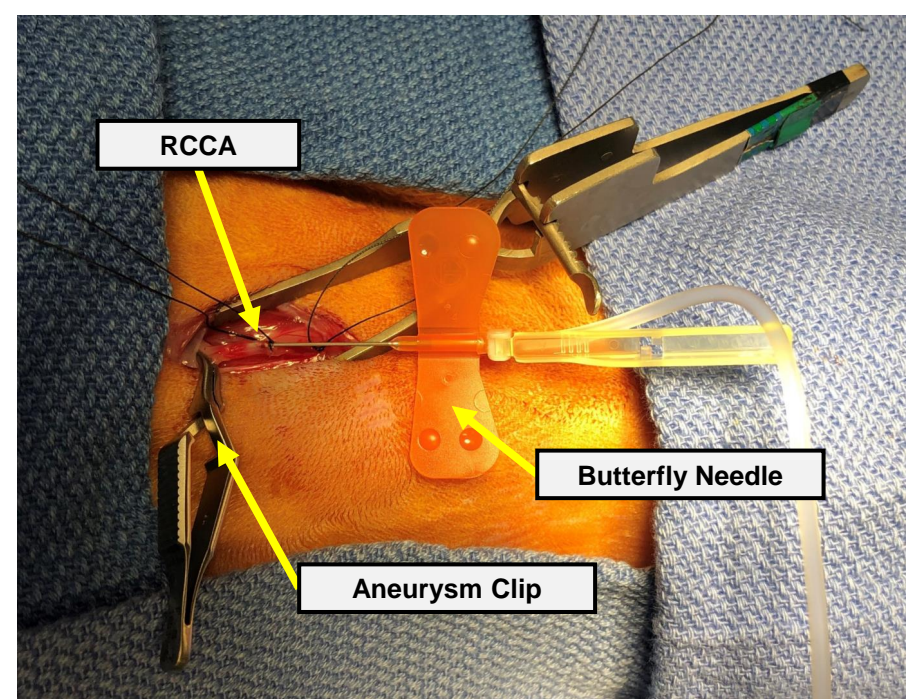

(b)

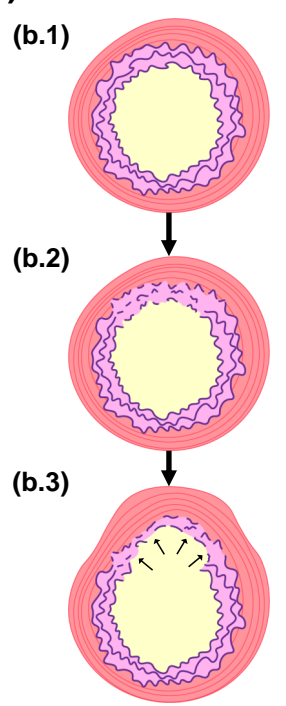

Figure 2: (a) Surgical setup for aneurysm formation, showing the use of the butterfly catheter. (b) Schematic of aneurysm formation via elastase injection: (b.1) healthy vascular wall with integral elastic lamina, (b.2) elastic lamina degradation induced by elastase injection and (b.3) focal dilation of the arterial wall caused by the breakdown of the elastic lamina.

\subsection{Histology}

Resected aneurysms tissues and controls were processed with routine histology methods. Briefly, tissues were fixed in $10 \%$ formalin and embedded in paraffin. Tissue sections of $5-7 \mu \mathrm{m}$ of thickness were obtained using a microtome and stained with Verhoeff-elastic-Van Gieson stain. Tissue sections mounted on glass slides for light microscopy assessment. Digital histology images were obtained using a light microscope. Images were taken using a $4 \mathrm{X}$ objective and digitally merged using ImageJ (National Institutes of Health, USA). ${ }^{[28]}$

\subsection{Statistical Analysis}

All quantitative measurements are represented as mean \pm standard deviation. Animal groups were compared using ANOVA test, where differences were deemed significant when $p<0.05$. All statistical assessments were performed in SPSS (IBM Corp.).

\section{Results}

\subsection{Aneurysm Formation}

Male New Zealand white rabbits underwent successful aneurysm creation $(n=12)$. Average aneurysm length was $4.01 .9 \mathrm{~mm}$ (range $2.2-8.4 \mathrm{~mm}$ ) and an average width of $1.50 .4 \mathrm{~mm}$ (range 
bioRxiv preprint doi: https://doi org/10.1101/2021.10.08.463749; this version posted October 9 , 2021. The copyright holder for this preprint (which was not certified by peer review) is the author/funder, who has granted bioRxiv a license to display the preprint in perpetuity. It is made available under aCC-BY-NC 4.0 International license.

$1.0-2.3 \mathrm{~mm}$ ). Table 2 lists average aneurysm length and width at the investigated timepoints. ANOVA analysis returned no significant difference for length $(p=0.983)$ or width $(p=0.401)$. Fig. 3 shows representative angiographic assessment of aneurysm formation at the RCCA.

Table 2: Raymond-Roy Occlusion Classification rates after treatment with current marketable endovascular devices.

\begin{tabular}{|c|c|c|}
\hline Timepoint & AL $(\mathrm{mm})$ & AW $(\mathrm{mm})$ \\
\hline 2 weeks & $4.2 \pm 2.8$ & $1.3 \pm 0.3$ \\
\hline 4 weeks & $3.9 \pm 1.0$ & $1.4 \pm 0.2$ \\
\hline 6 weeks & $3.9 \pm 1.8$ & $1.7 \pm 0.4$ \\
\hline
\end{tabular}

\subsection{Histological Assessment}

Histological sections were succesfully obtained from the resected aneurysms. Tissue sections exhibited the classic structure for the arterial wall of the aneurysm. Specifically, Verhoeff-Van Gieson stain allowed the observation of the elastic fibers in the vascular wall, which were observed as the darker purple tone in Fig. 4. Our results indicate a generalized deficiency of elastic fibers in the aneurysm wall, where we even observed regions sections with complete absence of these elastic structures. Additionally, we observed that the aneurysms of the 6-week group exhibited an evident lack of structure in the elastic fibers (Fig. 4c), while the other two time points still exhibited some fragments elastic lamina (Fig. 4a,b).

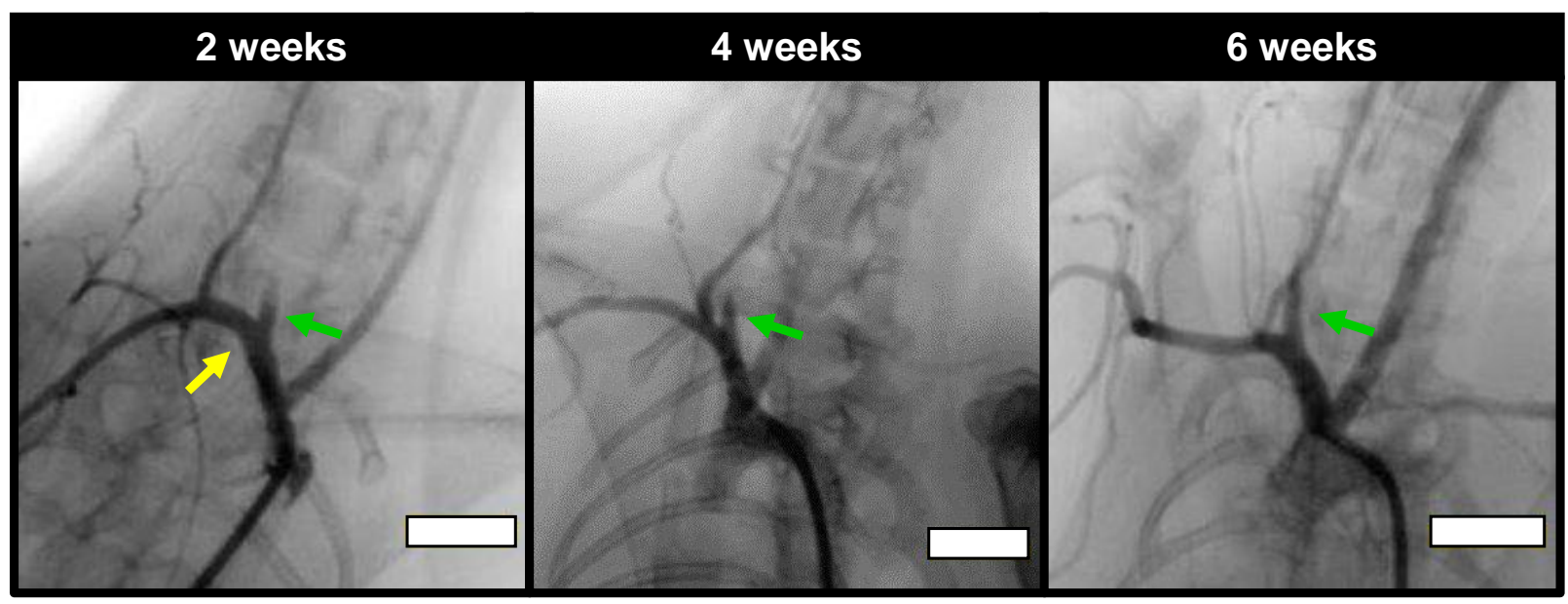

Figure 3: Representative angiograms of the created aneurysms. The green arrows point towards the created aneurysms and the yellow arrow indicates the RCCA. Scale bars $=10 \mathrm{~mm}$ ) 
bioRxiv preprint doi: $h$ ttps://doi.org/10.1101/2021.10.08 463749; this version posted October 9, 2021. The copyright holder for this preprint (which was not certified by peer review) is the author/funder, who has granted bioRxiv a license to display the preprint in perpetuity. It is made available under aCC-BY-NC 4.0 International license.

(a)

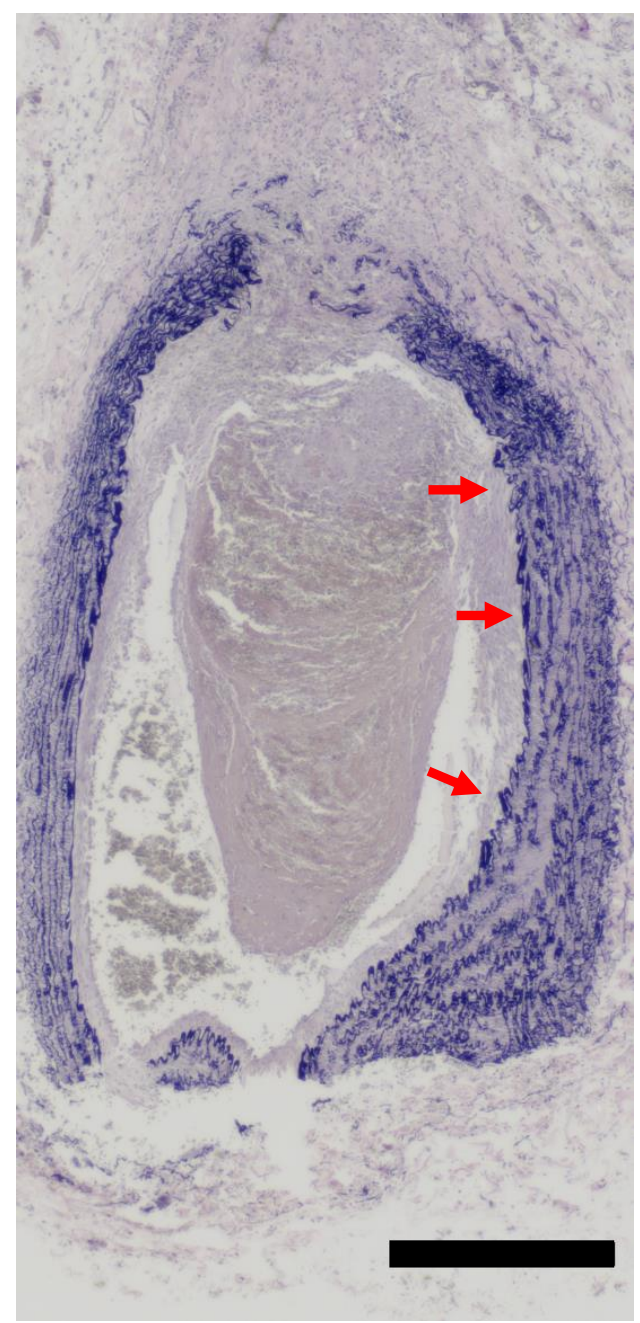

(b)

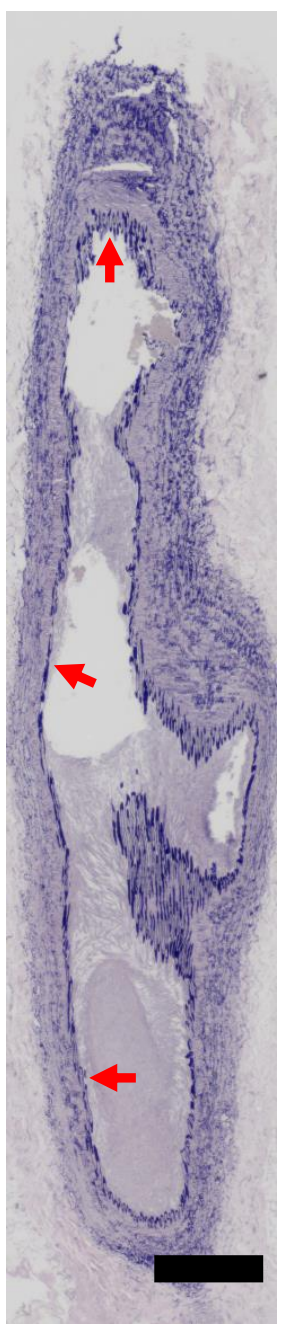

(c)

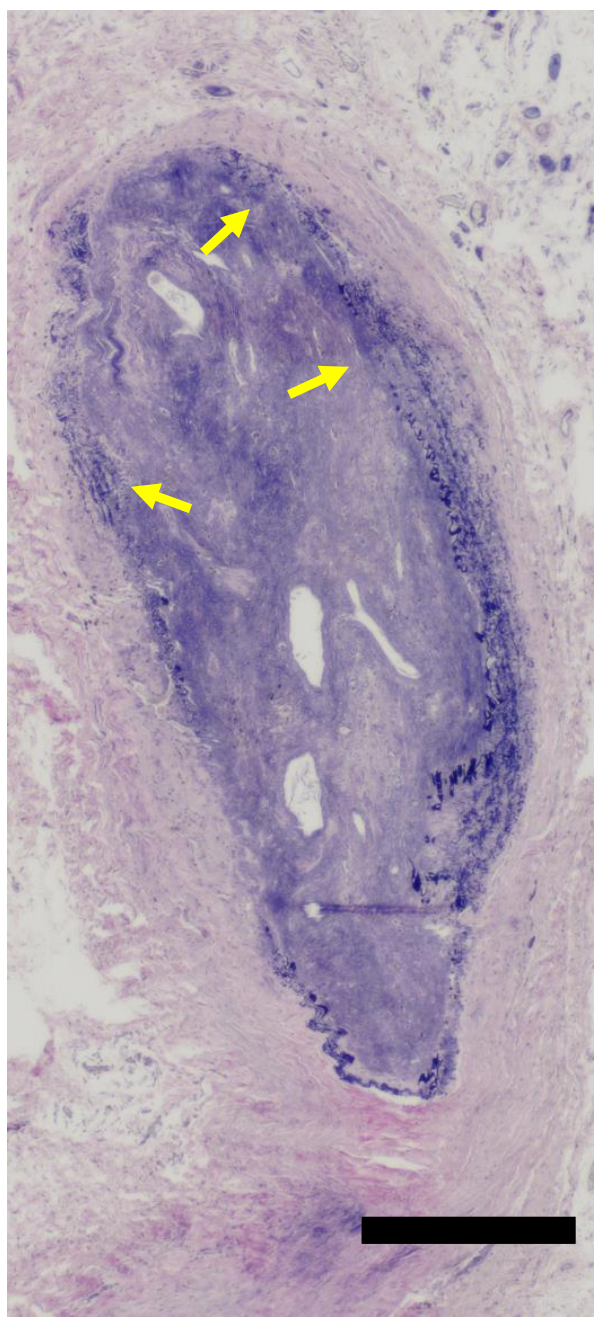

Figure 4: Histology slides of the created aneurysms depicting elastin degradation at (a) 2 weeks, (b) 4 weeks, and (c) 6 weeks. Red arrows indicate the portions of the non-degraded elastic lamina. Yellow arrows indicate the degradation of the elastic fibers. Scale bars $=0.5 \mathrm{~mm}$.

\section{Discussion}

\subsection{Our approach}

Technology for endovascular embolization of intracranial aneurysms has advanced significantly over the last thirty years since the development of GDCs. Further innovation in the field requires the development of pre-clinical models that allow testing of safety and efficacy of endovascular devices. To this end, animal models for saccular aneurysms have been developed and improved over the past six decades. ${ }^{[29-31]}$ These models have been able to accurately mimic the anatomy and hemodynamics of human aneurysms using different species, including mice, rats, rabbits, among several others. Specif- 
ically, the rabbit model has proved to be superior for the testing of endovascular devices, due to the docility of the animal, low maintenance cost, wide availability and appropriate size for the formation of aneurysms with similar geometry to the human. ${ }^{[25]}$

Among the different aneurysm formation techniques in the rabbit model, elastase injection is described as a fast alternative for the formation of aneurysms prone to rupture. ${ }^{[25]}$ In this procedure, successful elastase injection requires proximal and distal ligation of the common carotid artery (CCA), which is consistently described to included the dissection of the parent artery and the use of a silk tie for distal ligation of the CCA. Currently, two techniques for proximal ligation of the vessel are extensively applied: (i) the use of a Fogarty balloon ${ }^{[32]}$, or (ii) use of a temporary aneurysm clip. ${ }^{[33]}$ Based on our experience, we agreed with Hoh et al. about the potential damage to the CCA when using the Fogarty balloon. Therefore, we have adapted the method as described by Hoh et al. and aimed at its improvement.

Hoh et al. used of an angiocatheter to inject elastase between the proximal and distal ligation sites and it was maintained in the intraluminal space for the 20 -minute elastase injection time. We initially performed our aneurysm formation with the angiocatheter but we noticed that it had the potential to cause torque on the vessel. In addition, it was not only more difficult to insert the catheter into the CCA initially, but it placed unwanted pressure on the sides of the arterial wall. These complications during elastase injection might lead to unwanted vessel lesion and and remodeling processes on the artery, ultimately altering the native condition of the healthy artery wall. ${ }^{[34]}$ As a result, we have substituted the use of the angiocatheter for a butterfly catheter to reduce the potential application of torque. This modification of the protocol allowed the surgical team to to step back from the table and inject elastase from the opposite end of the catheter without risk of vessel damage. As a result, we have been able to induce the formation of stable saccular aneurysms via elastic lamina degradation, as demonstrated in Fig. 3 and Fig. 4. We believe that this modification to the aneurysm formation protocol can provide significant improvement to the ease-of-use of this animal model.

\subsection{Applications for Endovascular Device Testing}

Formation of saccular aneurysms for the testing of endovascular devices requires the maintenance of native properties in the parent artery, as off-target damages during elastase injection might lead to unwanted vessel rupture or reduce effectiveness of the model, in addition to animal fatalities. In addition, damages to the vessel wall might also increase alterations in the vessel flow dynamics, limiting the accuracy of aneurysm computational flow dynamics research, which is paramount importance for the development of endovascular devices. ${ }^{[35]}$ 
Our findings in this modified protocol will be applied to the development of a novel coil-free endovascular device. We have developed a shape memory polymer (SMP) for endovascular embolization of patient-specific aneurysm geometries, ${ }^{[36-39]}$ and we believe that this elastase-induced aneurysm formation protocol can aid in the translation of our material to the pre-clinical setting. We plan to test our material with a statistically powerful sample size, to determine the pre-clinical safety and effectiveness of our SMP device (measured using RROC scale, Fig. 1). We also plan on studying the microstructural and mechanical properties of the aneurysms formed in this animal model, and compare them to our recent findings in the properties of a human aneurysm specimen. ${ }^{[40]}$ Lastly, this animal model can also be used for training of surgical teams in the deployment of current marketable endovascular devices. ${ }^{[41]}$

\subsection{Study Limitations}

The key advantage of this technique over similar techniques is the significant reduction in the torque on the artery. While this is not necessarily stated as an issue in the literature, we experienced vessel torsion while using an angiocatheter and injecting the elastase solution. To minimize the risk of injury, it was imperative that we substitute the angiocatheter, which was done by using a butterfly catheter. We also found that, while the balloon catheter method was effective, this step required more time than was necessary to achieve the same result. While we did not encounter any short term complications from our procedure, or any post-operative complications with any of the animals, it would be advantageous to replicate this protocol with more samples and/or a longer study period.

\section{Conclusion}

In this study, we present a modification to traditional elastase-induced aneurysm models. We have substituted the use of an angiocatheter for elastase injection for a butterfly catheter, which reduced the applied torque on the artery, reducing the potential for parent vessel injury. We believe that this modification to the traditional elastase/RCCA-ligation method can further improve aneurysm modeling in rabbit animal models. This method improvement has important implications for the in vivo testing of endovascular devices and training for ICA embolization procedures.

Acknowledgments. We would like to acknowledge the supported granted by the Oklahoma Center for the Advancement of Science and Technology (OCAST) Health Research Program (HR18002), the Oklahoma Shared Clinical and Translational Resources (OSCTR) Pilot Projects Program (NIGMSU54GM104938), and the institutional funding from the VPRP Office and the Institute for Biomedical Engineering, Science and Technology (IBEST) at the University of Oklahoma.

Conflict of Interest: The authors declare no conflict of interest in the presented work.. 
bioRxiv preprint doi: https://doi.org/10.1101/2021.10.08.463749; this version posted October $9,2021$. The copyright holder for this preprint (which was not certified by peer review) is the author/funder, who has granted bioRxiv a license to display the preprint in perpetuity. It is made available under aCC-BY-NC 4.0 International license.

\section{References}

[1] N. Etminan, H.-S. Chang, K. Hackenberg, N. K. de Rooij, M. D. I. Vergouwen, G. J. E. Rinkel, A. Algra, Worldwide Incidence of Aneurysmal Subarachnoid Hemorrhage According to Region, Time Period, Blood Pressure, and Smoking Prevalence in the Population: A Systematic Review and Meta-analysis, JAMA Neurology 76 (5) (2019) 588-597. doi:10.1001/jamaneurol.2019.0006.

[2] S. Juvela, M. Porras, K. Poussa, Natural history of unruptured intracranial aneurysms: probability of and risk factors for aneurysm rupture, Journal of Neurosurgery 93 (3) (2000) $379-387$. doi:10.3171/jns.2000.93.3. 0379.

[3] M. Sonobe, T. Yamazaki, M. Yonekura, H. Kikuchi, Small unruptured intracranial aneurysm verification study, Stroke 41 (9) (2010) 1969-1977. doi:10.1161/STROKEAHA.110.585059.

[4] R. Kleinloog, N. de Mul, B. H. Verweij, J. A. Post, G. J. E. Rinkel, Y. M. Ruigrok, Risk Factors for Intracranial Aneurysm Rupture: A Systematic Review, Neurosurgery 82 (4) (2017) 431-440. doi:10.1093/neuros / nyx238.

[5] M. J. Wermer, I. C. van der Schaaf, A. Algra, G. J. Rinkel, Risk of rupture of unruptured intracranial aneurysms in relation to patient and aneurysm characteristics, Stroke 38 (4) (2007) 1404-1410. doi:10.1161/01. STR. $0000260955.51401 . \mathrm{cd}$.

[6] A. I. Qureshi, V. Janardhan, R. A. Hanel, G. Lanzino, Comparison of endovascular and surgical treatments for intracranial aneurysms: an evidence-based review, The Lancet Neurology 6 (9) (2007) 816-825. doi : https: //doi.org/10.1016/S1474-4422(07)70217-X.

[7] K. M. Fargen, H. E. Soriano-Baron, J. T. Rushing, W. Mack, J. Mocco, F. Albuquerque, A. F. Ducruet, M. Mokin, I. Linfante, S. Q. Wolfe, J. A. Wilson, J. A. Hirsch, A survey of intracranial aneurysm treatment practices among united states physicians 10 (1) (2018) 44-49. doi:10.1136/neurintsurg-2016-012808.

[8] G. Guglielmi, F. Viñuela, I. Sepetka, V. Macellari, Electrothrombosis of saccular aneurysms via endovascular approach: Part 1: Electrochemical basis, technique, and experimental results, Journal of Neurosurgery 75 (1) (1991) 1 - 7. doi:10.3171/jns.1991.75.1.0001.

[9] G. Guglielmi, F. Viñuela, J. Dion, G. Duckwiler, Electrothrombosis of saccular aneurysms via endovascular approach: Part 2: Preliminary clinical experience, Journal of Neurosurgery 75 (1) (1991) 8-14. doi:10.3171/ jns . 1991. 75.1 .0008$.

[10] M. Piotin, R. Blanc, Balloons and stents in the endovascular treatment of cerebral aneurysms: Vascular anatomy remodeled, Frontiers in Neurology 5 (2014) 41. doi:10.3389/fneur.2014.00041.

[11] I. Szikora, M. Marosfői, B. Salomváry, Z. Berentei, I. Gubucz, Resolution of mass effect and compression symptoms following endoluminal flow diversion for the treatment of intracranial aneurysms 34 (5) (2013) 935-939. doi: 10.3174/ajnr.A3547.

[12] A. J. Molyneux, R. S. Kerr, L.-M. Yu, M. Clarke, M. Sneade, J. A. Yarnold, P. Sandercock, International subarachnoid aneurysm trial (isat) of neurosurgical clipping versus endovascular coiling in 2143 patients with ruptured intracranial aneurysms: a randomised comparison of effects on survival, dependency, seizures, rebleeding, subgroups, and aneurysm occlusion, The Lancet 366 (9488) (2005) 809-817. doi:https://doi.org/10. 1016/S0140-6736(05)67214-5.

[13] S. K. Mendenhall, D. H. Sahlein, C. D. Wilson, A. C. Filley, J. Ordaz, R. K. Ahluwalia, W. A. Bakare, A. Huh, E. Dancour, M. A. Zaazoue, S. A. Shapiro, A. A. Cohen-Gadol, The natural history of coiled cerebral aneurysms stratified by modified raymond-roy occlusion classification, World Neurosurgery 128 (2019) e417-e426. doi: https://doi.org/10.1016/j.wneu.2019.04.167.

[14] A. M. Spiotta, M. S. Park, R. J. Bellon, B. N. Bohnstedt, A. J. Yoo, C. M. Schirmer, R. A. DeLeacy, D. J. Fiorella, B. K. Woodward, H. E. Hawk, A. Nanda, O. O. Zaidat, P. J. Sunenshine, K. C. Liu, M. R. Kabbani, K. V. Snyder, T. Sivapatham, T. M. Dumont, A. R. Reeves, R. M. Starke, T. S. R. I. , The smart registry: Long-term results on the utility of the penumbra smart coil system for treatment of intracranial aneurysms and other malformations, Frontiers in Neurology 12 (2021) 478. doi:10.3389/fneur.2021.637551.

[15] C. A. Taschner, R. Chapot, V. Costalat, P. Machi, P. Courthéoux, X. Barreau, J. Berge, L. Pierot, K. Kadziolka, B. Jean, R. Blanc, A. Biondi, H. Brunel, S. Gallas, A. Berlis, D. Herbreteau, J. Berkefeld, H. Urbach, S. Elsheikh, J. Fiehler, H. Desal, E. Graf, A. Bonafé, Second-generation hydrogel coils for the endovascular treatment of intracranial aneurysms, Stroke 49 (3) (2018) 667-674. doi:10.1161/STROKEAHA.117.018707.

[16] B. R. Bendok, K. R. Abi-Aad, J. D. Ward, J. F. Kniss, M. J. Kwasny, R. J. Rahme, S. G. Aoun, T. Y. El Ahmadieh, N. E. El Tecle, S. G. Zammar, R. J. N. Aoun, D. P. Patra, S. A. Ansari, J. Raymond, H. H. Woo, D. Fiorella, G. Dabus, G. Milot, J. E. Delgado Almandoz, J. A. Scott, A. J. DeNardo, S. R. Dashti, H. S. Investigators, The Hydrogel Endovascular Aneurysm Treatment Trial (HEAT): A Randomized Controlled Trial of the Second-Generation Hydrogel Coil, Neurosurgery 86 (5) (2020) 615-624. doi:10.1093/neuros / nyaa006.

[17] X. Yao, J. Ma, H. Li, H. Shen, X. Lu, G. Chen, Safety and efficiency of flow diverters for treating small intracranial 
bioRxiv preprint doi: https://doi.org/10.1101/2021.10.08.463749; this version posted October 9,2021 . The copyright holder for this preprint (which was not certified by peer review) is the author/funder, who has granted bioRxiv a license to display the preprint in perpetuity. It is made available under aCC-BY-NC 4.0 International license.

aneurysms: A systematic review and meta-analysis, Journal of International Medical Research 45 (1) (2017) 11-21, pMID: 28222628. doi:10.1177/0300060516671600.

[18] A. S. Arthur, A. Molyneux, A. L. Coon, I. Saatci, I. Szikora, F. Baltacioglu, A. Sultan, D. Hoit, J. E. Delgado Almandoz, L. Elijovich, S. Cekirge, J. V. Byrne, D. Fiorella, The safety and effectiveness of the woven endobridge (web) system for the treatment of wide-necked bifurcation aneurysms: final 12-month results of the pivotal web intrasaccular therapy (web-it) study, Journal of NeuroInterventional Surgery 11 (9) (2019) 924-930. doi:10.1136/neurintsurg-2019-014815.

[19] N. Goyal, D. Hoit, J. DiNitto, L. Elijovich, D. Fiorella, L. Pierot, S. Lamin, L. Spelle, I. Saatci, S. Cekirge, A. S. Arthur, How to web: a practical review of methodology for the use of the woven endobridge, Journal of NeuroInterventional Surgery 12 (5) (2020) 512-520. doi:10.1136/neurintsurg-2019-015506.

[20] T. Ries, S. Siemonsen, G. Thomalla, U. Grzyska, H. Zeumer, J. Fiehler, Long-term follow-up of cerebral aneurysms after endovascular therapy-prediction and outcome of retreatment, American Journal of Neuroradiology 28 (9) (2007) 1755-1761. doi:10.3174/ajnr.A0649.

[21] V. M. Tutino, M. Mandelbaum, A. Takahashi, L. C. Pope, A. Siddiqui, J. Kolega, H. Meng, Hypertension and estrogen deficiency augment aneurysmal remodeling in the rabbit circle of willis in response to carotid ligation, The Anatomical Record 298 (11) (2015) 1903-1910. doi: https://doi.org/10.1002/ar.23205.

[22] T. Ikedo, M. Minami, H. Kataoka, K. Hayashi, M. Nagata, R. Fujikawa, S. Higuchi, M. Yasui, T. Aoki, M. Fukuda, M. Yokode, S. Miyamoto, Dipeptidyl peptidase\&\#x2010;4 inhibitor anagliptin prevents intracranial aneurysm growth by suppressing macrophage infiltration and activation, Journal of the American Heart Association 6 (6) (2017) e004777. doi:10.1161/JAHA.116.004777.

[23] M. Killer, D. Kallmes, R. Jones, Y. Ding, M. Vestal, T. Hauser, R. Virmani, G. Cruise, Long-term angiographic and histological results of a new hydrogel-containing filling coil in experimental rabbit aneurysms, Minim Invasive Neurosurg 53 (3) (2010) 97-105. doi:10.1055/s-0030-1252059.

[24] J. Raymond, J.-C. Gentric, T. E. Darsaut, D. Iancu, M. Chagnon, A. Weill, D. Roy, Flow diversion in the treatment of aneurysms: a randomized care trial and registry, Journal of Neurosurgery JNS 127 (3) (2017) 454 - 462 . doi : $10.3171 / 2016.4$. JNS152662.

[25] F. Strange, B. E. Grüter, J. Fandino, S. Marbacher, Preclinical intracranial aneurysm models: A systematic review, Brain Sciences 10 (3) (2020). doi: 10.3390 /brainsci10030134.

[26] S. M. Herting, Y. Ding, A. J. Boyle, D. Dai, L. D. Nash, S. Asnafi, D. R. Jakaitis, C. R. Johnson, L. M. Graul, C. Yeh, D. F. Kallmes, R. Kadirvel, D. J. Maitland, In vivo comparison of shape memory polymer foam-coated and bare metal coils for aneurysm occlusion in the rabbit elastase model, Journal of Biomedical Materials Research Part B: Applied Biomaterials 107 (8) (2019) 2466-2475. doi : https: / / doi .org/10.1002/ jbm.b.34337.

[27] Y.-H. Ding, D. Dai, D. Schroeder, R. Kadirvel, D. F. Kallmes, Experimental testing of the dual-layer woven endobridge device using an elastase-induced aneurysm model in rabbits, Interventional Neuroradiology 22 (3) (2016) 299-303, pMID: 26847799. doi :10.1177/1591019916628202.

[28] J. Schindelin, I. Arganda-Carreras, E. Frise, V. Kaynig, M. Longair, T. Pietzsch, S. Preibisch, C. Rueden, S. Saalfeld, B. Schmid, J.-Y. Tinevez, D. J. White, V. Hartenstein, K. Eliceiri, P. Tomancak, A. Cardona, Fiji: an open-source platform for biological-image analysis, Nature Methods 9 (7) (2012) 676-682. doi : 10 . 1038 / nmeth. 2019.

[29] W. J. German, S. P. W. Black, Experimental production of carotid aneurysms, New England Journal of Medicine 250 (3) (1954) 104-106, pMID: 13119853. doi:10.1056/NEJM1 95401212500303.

[30] W. Brinjikji, Y. H. Ding, D. F. Kallmes, R. Kadirvel, From bench to bedside: utility of the rabbit elastase aneurysm model in preclinical studies of intracranial aneurysm treatment, Journal of NeuroInterventional Surgery (2015). do i : $10.1136 /$ neurintsurg-2015-011704.

[31] H. J. Cloft, T. A. Altes, W. F. Marx, R. J. Raible, S. B. Hudson, G. A. Helm, J. W. Mandell, M. E. Jensen, J. E. Dion, D. F. Kallmes, Endovascular creation of an in vivo bifurcation aneurysm model in rabbits, Radiology 213 (1) (1999) 223-238, pMID: 10540666. doi:10.1148/radiology.213.1.r99oc15223.

[32] Y. Ding, D. Dai, R. Kadirvel, D. Lewis, D. Kallmes, Five-year follow-up in elastase-induced aneurysms in rabbits, American Journal of Neuroradiology 31 (7) (2010) 1236-1239. doi:10.3174/a jnr.A2056.

[33] B. L. Hoh, J. D. Rabinov, J. C. Pryor, C. S. Ogilvy, A modified technique for using elastase to create saccular aneurysms in animals that histologically and hemodynamically resemble aneurysms in human, Acta Neurochirurgica 146 (7) (2004) 705-711. doi:10.1007/s00701-004-0276-6.

[34] H.-C. Han, Q. Liu, Z.-L. Jiang, Mechanical behavior and wall remodeling of blood vessels under axial twist, Yi yong sheng wu li xue 31 (4) (2016) 319-326.

[35] R. Bodlak, Computational investigations of a shape-memory polymer foam embolization device for intracranial aneurysms (2021).

[36] S. A. Pineda-Castillo, J. Luo, H. Lee, B. N. Bohnstedt, Y. Liu, C.-H. Lee, Effects of carbon nanotube infiltration on a shape memory polymer-based device for brain aneurysm therapeutics: Design and characterization of a joule-heating triggering mechanism, Advanced Engineering Materials 23 (6) (2021) 2100322. doi : https : / / doi . org/10 . 
bioRxiv preprint doi: https://doi.org/10.1101/2021.10.08.463749; this version posted October 9, 2021. The copyright holder for this preprint (which was not certified by peer review) is the author/funder, who has granted bioRxiv a license to display the preprint in perpetuity. It is made available under aCC-BY-NC 4.0 International license.

1002 / adem. 202100322.

[37] R. Kunkel, D. Laurence, J. Wang, D. Robinson, J. Scherrer, Y. Wu, B. Bohnstedt, A. Chien, Y. Liu, C.-H. Lee, Synthesis and characterization of bio-compatible shape memory polymers with potential applications to endovascular embolization of intracranial aneurysms, Journal of the Mechanical Behavior of Biomedical Materials 88 (2018) 422 430. doi:https://doi.org/10.1016/j.jmbbm.2018.08.037.

[38] H. Fisher, P. Woolard, C. Ross, R. Kunkel, B. N. Bohnstedt, Y. Liu, C.-H. Lee, Thermomechanical data of polyurethane shape memory polymer: Considering varying compositions, Data in Brief 32 (2020) 106294. doi: https://doi.org/10.1016/j.dib.2020.106294.

[39] J. Wang, J. Luo, R. Kunkel, M. Saha, B. N. Bohnstedt, C.-H. Lee, Y. Liu, Development of shape memory polymer nanocomposite foam for treatment of intracranial aneurysms, Materials Letters 250 (2019) 38-41. doi: https: //doi.org/10.1016/j.matlet.2019.04.112.

[40] D. W. Laurence, H. Homburg, F. Yan, Q. Tang, K.-M. Fung, B. N. Bohnstedt, G. A. Holzapfel, C.-H. Lee, A pilot study on biaxial mechanical, collagen microstructural, and morphological characterizations of a resected human intracranial aneurysm tissue, Scientific Reports 11 (1) (2021) 3525. doi : 10.1038 /s 41598-021-82991-x.

[41] U. Spetzger, A. von Schilling, T. Brombach, G. Winkler, Training models for vascular microneurosurgery, Acta Neurochir Suppl 112 (2011) 115-9. doi:10.1007/978-3-7091-0661-7_21. 